\title{
1 The Handbook on the Sustainable Supply Chain: an introduction
}

Joseph Sarkis

\subsection{INTRODUCTION}

Corporate sustainability has a long and evolving history. Multiple global stakeholders have arrived at a consensus that man's influence and relationship to nature has not always been mutually beneficial. Man has gained, usually at the expense of the natural environment. Some of the greatest influences man has on nature are through the production and consumption of resources. It is from this perspective that in this book we study the theory, practice, and phenomena that exist in industrial and commercial supply chains.

Another aspect is that we consider sustainability. Although the term 'sustainability' is used in this Handbook, much of the book's content is focused on ecological or environmental sustainability. The term 'green' is used often throughout the book, which could have easily been titled 'Green Supply Chain Management'.

The term 'sustainability' extends to incorporate social and economic concerns, based on the triple-bottom-line definition of sustainability. But the inclusion of these additional non-ecological dimensions can be problematic. The problem arises when anthropocentric values, rather than biocentric or ecocentric perspectives, dominate the sustainability discussion. In practice and in research, sustainability can easily get bounded in what is best for man, and not necessarily what is the best for the natural environment. Given that research, and this book, are targeting human needs, this central tension will exist, but cannot be ignored.

My philosophy is that man and economy fit within the natural environment, and that man is only a part of the broader ecosystem. If humans destroy the natural environment, they are destroying themselves and their social and economic systems. Thus, the natural environment takes a lead role in this book.

Another thematic aspect of the Handbook is that focusing on organizations alone and separately may provide only some, fractional, opportunities for improving environmental and economic sustainability. The greatest influences and opportunities occur across and between organizations. Thus, the supply chain is critical for a more complete, systemic and holistic perspective of sustainability concerns caused by commerce and industry.

These are important motivations for this Handbook and the concepts included within. The scope of the book is quite broad and incorporates a broad variety of perspectives and approaches to understand these perspectives. We have tried to make the Handbook accessible to multiple audiences: practitioners, academics, students, and people interested in understanding our world.

In this introductory chapter some general thoughts about sustainable supply chains are first presented. I try not to focus on definitions since each chapter provides a definition. Although there are commonalities in definitions, there may also be differences, so careful 
reading and understanding of some of the foundations of a given chapter is a prudent approach in reading the book. In the remainder of this introductory chapter, I review a short and recent history of sustainability in supply chains. Then a hierarchical and process perspective of topics and concerns is presented. An outline of the book follows, where content and some interrelationships and structure of topics are presented.

\subsection{SUPPLY CHAINS AND SUSTAINABILITY}

There are a variety of definitions of supply chains and sustainability in the literature. In each of this book's chapters you will also find slight definitional variations. Supply chain management has a long history as part of industry and commerce. Many of the activities that currently define most supply chains have existed since early commerce eras. Whether we are speaking of a craft, one-of-a-kind production, or mass production manufacturers, or services environments, supply chains exist.

Supply chains consist of multiple organizations and inter-organizational relationships. Upstream supply chains usually involve purchasing and inbound logistics. Downstream supply chains involve customers, including industrial and individual customers. Closing the loop brings materials and goods back into the forward supply chain. Closed-loop supply chains take the linear model of supply chains and incorporate reverse logistics and supply chains. Supply chain definition variations also result from where the supply chain boundary is drawn. For example, some researchers may focus only on upstream supplier activities, while others may consider the broader supply chain networks that cover global supply chains. Some of these levels of analysis are discussed in the next section of this chapter.

The content in this book focuses on the term 'supply chain'. Yet, non-business and nonengineering fields and disciplines, such as geography and political science, have studied supply chains, but may use the term 'value chain'. Additionally, some fields broadly consider the term 'interorganizational strategies and practices'. Whatever term is used, the focus on multiple organizations and their relationships, the involvement of external stakeholders and actors such as governmental agencies, communities, academic institutions, and non-governmental organizations (NGOs), can be included in these studies.

Sustainability has its underpinnings in literature related to natural ecological concerns, in addition to corporate social responsibility and business ethics fields. Broadly, sustainable development has also been used to further refine and define sustainability. Sustainability has many definitions, but as alluded to earlier in this chapter, includes triple-bottom-line dimensions. The other common definition of sustainability is the intergenerational philosophy of helping future generations thrive. A long-term and multidimensional perspective is central to sustainability. This characteristic also leads to many managerial complexities.

The managerial complexities associated with sustainability, added to the many players and activities contributing to supply chain complexities, results in greater managerial and decision uncertainties and difficulties for modern corporations and their stakeholders. These complexities are evident in almost every chapter presented in this book. It also provides a rich and fertile field for research and improvement.

Some of the early published research investigating multi-organizational or inter- 
organizational activities and environmental concerns is found in the economics literature. For example, almost 50 years ago studies were published that focused on simulating interorganizational activities, production and consumption, that caused global climate change, and evaluating these results (Ayres and Kneese, 1969). This publication example also points to the fact that environmentally sustainable supply chain studies have been occurring for decades and are not a recent phenomenon or fad.

\subsection{AN EVOLUTION AND RELATIONSHIPS IN SUSTAINABLE SUPPLY CHAINS}

Social and environmental issues and the role of industry have been a concern for centuries. Whether we are considering the social concerns associated with Dickensian England, or the industrial revolution and the turn-of-the-century social and health concerns with food production and Upton Sinclair's The Jungle (Sinclair, 1906), industrial and social concerns have overlapped.

Corporate social responsibility (CSR) was the major focus, with the emphasis on social issues facing man. The major topics in this area focused on human rights and philanthropy and giving to communities (Carroll, 2008). The 'father' of corporate social responsibility in his book mentioned the conservation of natural resources as the major environmental initiative within CSR (Bowen, 1953). The natural environment is one of many concerns in CSR, and in the CSR literature the natural environment does not take a central role. Additionally, its definition focusing on conservation misses the broader issues of environmentalism and greening.

Economics has historically considered environmental and social concerns as externalities that are to be modelled and considered through taxes or other regulatory mechanisms. Pigouvian taxes are at the centre of many environmental regulations to deter environmentally poor practices by organizations. Taxing can put a true cost on socially and environmentally degrading practices, while the extra revenue can be used to incentivize good practices, the 'double dividend'. There have been ethical criticisms of these taxes because it is felt that they give organizations a right to pollute.

Corporate environmental policy and practices were also greatly influenced by Rachel Carson's (1962) Silent Spring. The chemical and pesticide industry felt the concerns addressed in this book, where seemingly harmless and socially beneficial pesticides had long-term health and environmental concerns. The book set the stage for many regulations in the United States (US) and also raised international awareness. Arguably, the United States Environmental Protection Agency, although focused primarily on human health, evolved from the social forces and attention given by Carson's book.

The chemical industry and organizational environmental history with respect to environmentalism is well documented from a norms and rules, institutional, perspective in From Heresy to Dogma (Hoffman, 2001). The book describes the evolution of ecological sustainability, environmentalism, from being anathema to private for-profit organizations to a situation where it has become accepted and expected practice. Although there is some concern that environmentalism and sustainability have been co-opted by private enterprise (Welford, 1997).

Optimistic perspectives of industry changing its ways due to regulations and normative 
pressures, and more sanguine, sceptical perspectives associated with greenwashing, have been central to the polemics associated with corporate environmentalism. Although these controversies are not explicitly investigated in this book, there are concerns that underly each of the chapters. What is and what is not effective for supply chain sustainability is a thread in almost every chapter.

Economic perspectives of corporate environmental sustainability evolved to more fully incorporate broader perspectives beyond the individual organization to the supply chain. This expanded corporate environmental perspective and its linkage to the supply chain gained greater traction in practice and in academia, as the term 'supply chain' became more common industrial and academic parlance. Green operations, environmentally conscious manufacturing, cleaner production, sustainable consumption and production, green logistics, green purchasing, green supply chain management, closed-loop supply chains and a variety of other terms started to become more common terms in corporate environmental sustainability discourse.

The circular economy introduced broader macroeconomic principles associated with supply chain management. Broader policies evolved. Policies that supported infrastructure for closed-loop and sustainable supply chain development were implemented in the 1990s. These efforts garnered renewed interest in the 2000s. Industrial ecology and industrial symbiosis associated with managing resources more effectively grew simultaneously, with significant semantic and theoretical overlaps between these areas and sustainable supply chains. These integrative studies and practices continue today.

The United Nations Global Compact set forth its Millennial Development Goals (MDGs) at the turn of the century, evolving to the Sustainable Development Goals (SDGs) of the past few years (Sachs, 2012). These SDGs have implications for all dimensions of sustainable supply chains, and sustainable supply chains have implications for each of the 17 SDGs. Nations, organizations and participants in the SDGs and the Global Compact have recognized the importance of managing the industrial supply chain in an environmentally and socially conscious way to help achieve the SDGs.

Simultaneously with the general practices and philosophies, tools and technologies influencing and supporting sustainability of supply chains have also seen significant investigation and development. For example, life cycle analysis (LCA), design for the environment (DFE) and eco-design, and environmental management systems, have seen increased attention. The pervasiveness and preponderance of tools, models and methodologies have become a major subfield of study for corporate environmental sustainability (Brandenburg et al., 2014).

The complexities and concerns associated with sustainable supply chains have evolved over the years. The many dimensions of research and practice articles on green and sustainable supply chains cannot be captured in one book. A hierarchical perspective and viewpoint on sustainable supply chains can help to make sense of the topic and how it may be evaluated, studied, designed and implemented.

\subsection{A HIERARCHICAL MULTI-LEVEL PERSPECTIVE}

Identifying the scope of sustainable supply chains provides a way to help structure and understand this complex field. There are multiple levels of analysis and, with them, 


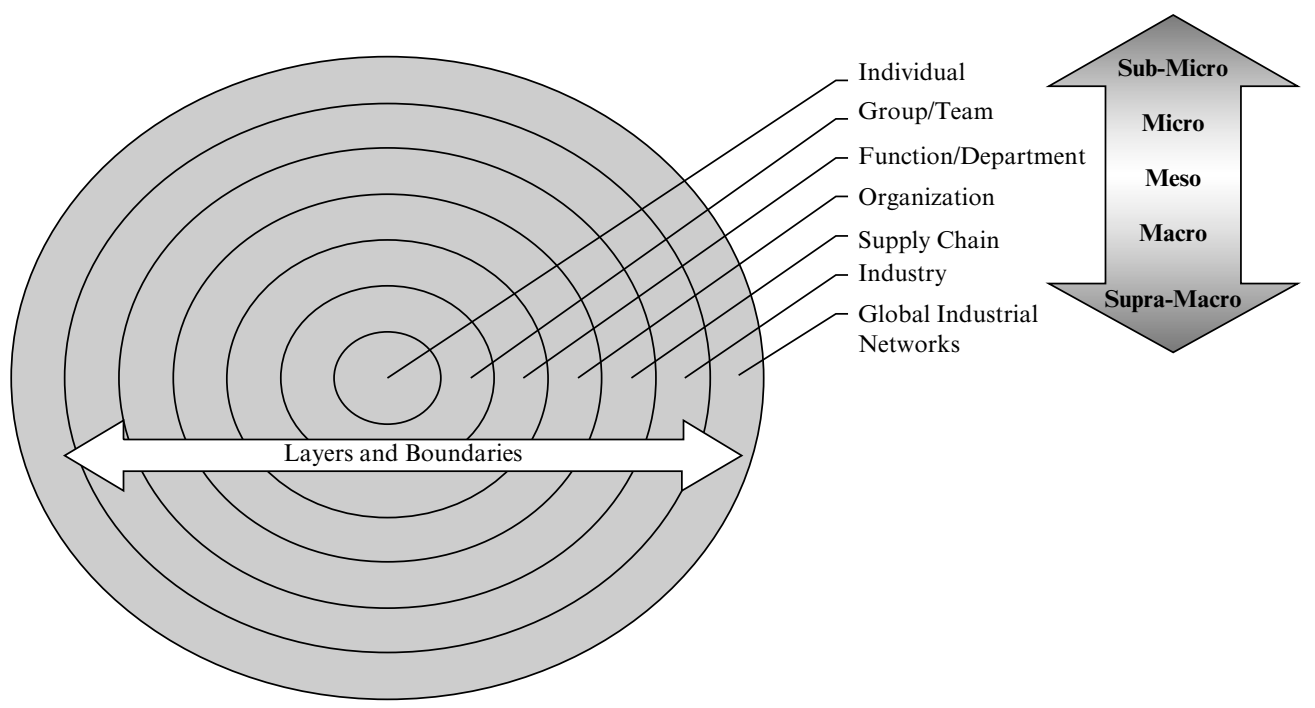

Figure 1.1 A hierarchical perspective for sustainable supply chains

boundaries to consider. One of the difficulties is identifying the boundaries and levels of analysis.

Concerns, issues and methodologies may vary and require some form of attention at each level. Figure 1.1 shows a potential set of hierarchies. Each of these aspects is considered in some way in each chapter. The level of analysis can range from individual, personal-level management (the sub-micro level) to global industrial networks (supra-macro).

At the individual level, principles such as cognitive decision-making of individuals, their values, motivations, behaviours and habits, need to be understood. At an individual level, personnel's roles in sustainable supply chain management are a focus. Lack of capabilities or motivation at the individual level can be problems associated with most topics introduced in this book. Organizational environmental psychological principles relating to leadership, motivation and pro-environmental behaviour may play important roles (Graves et al., 2013).

Groups of individuals form the next level. Groups or teams are necessary for successful implementation of various sustainable supply chain programmes and practices. Team formation is an example of such activity. Team skills and expertise need to be carefully managed in this complex environment. Not only do characteristics of individuals become an issue, but also their relationship dynamics. Supply chain teams can complement and build upon environmental knowledge and skills. Teamwork has a critical and direct relationship to sustainability innovation in the supply chain (Jabbour and Jabbour, 2016).

Departmental and functional levels can include procurement, marketing, engineering, and distribution and logistics organizational functions. Individuals and teams can accumulate at the departmental level. Various departments or functions within and between organizations will be necessary, given that sustainable supply chain activity requires multiple functions including marketing, information systems, purchasing, and supplier training (human resources). A group from the most-affected function is likely to lead the 
sustainability initiative. The culture and mindset of different functions, similarly to those of individuals, may vary and careful investigation is needed.

The literature and this book for the most part cover the organizational or enterpriselevel analysis. The organizational entity usually has the most responsibility for sustainability initiatives and performance. Much of the theory used to investigate and explain sustainable supply chain management occurs at the organizational level (e.g., Sarkis et al., 2011). How organizations act and interact in markets builds on organizational environmental governance, resources, processes and policies. The sphere of control at the organizational level is typically clear and legal. It is not as easy to draw the boundaries of control for supply chains.

Supply chains can range from a dyadic supply chain with only two organizations, to a network of companies. Partnerships between organizations, including strategic alliances and joint ventures, could be considered at this level. Managing multiple tiers in supply chains, as discussed in a number of chapters in this book, are at this level of analysis. Creative and unique perspectives are needed to advance understanding of supply chainlevel comparisons. Competing supply chains would target similar resources critical to their survival; and investigating across organizations is relatively complex.

At the industrial level, industries are relied upon to manage supply chain sustainability dimensions. There is evidence that industries and their governance associations set organizational and supply chain norms. These industry-specific certifications and associations help to diffuse sustainability standards along supply chains.

Global industrial networks can be supply chains that cover many regions of the world. Macroeconomic factors would be used for investigating sustainability at that level. Macroeconomic models such as input-output (I-O) analysis are tools frequently used in these investigations. Industrial networks and their trade can identify the impact of various products that occur in supply chains. International trade analyses along sustainability dimensions would need investigation. Typically, supply chain researchers have not investigated this level of analysis, focusing primarily on more organizational operational activities rather than international trade and business levels of analysis.

These levels of analysis all appear in this book. Some are more prevalent than others, but overall they are representative of the field. The book's content is now overviewed.

\subsection{OVERVIEW OF THE $H A N D B O O K$}

There are 33 chapters and more than 70 contributors in this Handbook, including this introductory chapter. This Handbook includes work from a number of international contributors from both theoretical and practical backgrounds, who share their research and experiences in sustainable supply chains. Most of the authors have published original research on the topic of their chapters. Initially, authors were given or proposed a general categorical topic in the field. Care was taken to provide a comprehensive view of the sustainable supply chain field. Many popular issues are covered, but given the complexity and breadth of the field, it is difficult to give an exhaustive treatment to the topics. For example, although alluded to in many chapters, actual analytical modelling and original case-based theoretically insightful articles are not included. The book is meant as an overview of current and future research and practice in the field. 
Each contributor was asked to overview the topic and provide some general insights from the literature and/or practice. Each chapter also provides avenues for future research and practice; some include general frameworks and slightly more detailed literature reviews. There is some overlap amongst chapters, but each one provides a unique perspective. Chapters are also meant to stand alone as topical readings.

In general, the early chapters focus on broader topics such as globalization and general strategies in the organization. Then, specific topics around functionally specific areas and sustainable supply chain practices and tools are included. Management and technology are two primary areas of focus in many of these chapters. Later chapters expand the scope somewhat to incorporate different industries, such as service and dimensions, including social and regulatory dimensions. Where possible, similar topics are juxtaposed for easy reader reference. I now provide a summary of chapters and some of their interlinkages.

\section{$1.6 \quad H A N D B O O K$ CONTENT OUTLINE}

Chapters 2 to 5 in this book focus on the broader issues facing sustainable supply chains. These broad perspectives, alluded to in early discussions in this introductory chapter, include globalization (Ibrahim, Chapter 2), circular economy (Liu et al., Chapter 3), general sustainable supply chain diffusion (Carmagnac et al., Chapter 4), and operational strategy issues (Ateş, Chapter 5). These broader concerns span borders of countries, industries, supply chains and organizations. Sustainable supply chain collaboration and coordination are broad philosophical and supply chain practices discussed in Chapter 6 (Zeng and Hou).

Chapters 7 to 11 go inside the organization, across various functions that either would be considered as part of the supply chain, or support the supply chain. For example, human resource management is an organizational support function covered in Chapter 7 (Jabbour and Jabbour), while the finance function is broadly represented in making the business case for sustainable supply chains (Meade and Presley, Chapter 8). Procurement through supplier selection (Rezaei, Chapter 9), green marketing (Dai et al., Chapter 10) and consumerism management (Groening and Zhu, Chapter 11) are core functional areas within the supply chain dealing with upstream and downstream stakeholders. One of the major concerns of the supply and value chain is the after-sales service and service supply chain, which may or may not parallel the products and goods supply chain. Services are broadly evaluated in Chapter 12 (Chen et al.).

Chapters 13 to 15 focus on innovation and design principles within the supply chain. Ambidexterity, a core topic of Chapter 13 (Yalcin and Schniederjans), focuses on the joint management of explorative and exploitative innovation. Chapters 14 and 15 utilize design of products (Alqahtani et al., Chapter 14) and the overall supply chain design (Varsei, Chapter 15) as two perspectives on sustainable innovative designs. Design activities also represent the early stages of sustainable supply chain management and are required before operational practices are completed in supply chain management.

Chapters 16 and 17 represent internal organizational supply chain activities related to manufacturing and operations. They represent some of the early internal organizational operational precursors to broader supply chain practices. Each of the chapters relates in some way to lean manufacturing practices, across the supply chain (Azevedo and 
Carvalho, Chapter 16) and in internal manufacturing practices (Vazquez-Brust and Campos, Chapter 17).

The next three chapters (Chapters 18-20) could have been interspersed amongst the other chapters in this Handbook, but are grouped together given their similarity on the topic of performance measures. For example, operational performance metrics and measurement (Sroufe and Melynk, Chapter 18) relate to the manufacturing and operations strategies topics of some earlier chapters in the book. Accounting and finance performance metrics (Beske-Janssen et al., Chapter 19) could fit with other financial and accounting management functional perspectives. The third chapter in this sequence addresses performance measurement within a standards and certifications context (Grant and Shaw, Chapter 20) which could be part of systems, multi-tier supply chains and sustainable supply chain diffusion topics.

Chapter 21 focuses on an important metric and measure when it comes to supply chain sustainability: that of greenhouse gas and carbon emissions (Goodarzi et al.). This chapter also provides a segue for Chapters 22-25, which include transportation, logistics and energy topics, all of which are major contributors to carbon emissions in the supply chain. Although emissions are a linking theme for these chapters, they also cover other important sustainable supply chain dimensions.

Logistics, in Chapter 22 (Marsillac and Hudson), is the movement and management of materials within the supply chain. The concept of planetary boundaries is introduced in this chapter as well. Transportation (Gurtu et al., Chapter 23) is critical to the movement of materials in logistics; and managing transportation sustainably can be completed through information technology and big data (Hu et al., Chapter 24). For transportation and information technology to function, energy is required (Halldórsson et al., Chapter 25); managing energy resources is critical from the resources depletion and emissions perspective of environmental supply chain sustainability.

Chapters 26 to 29 shift the focus to more social concerns; if not as a dimension, then as a practice. For example, social networks analysis (Tate and Ellram, Chapter 26) includes both broader diffusion and social concerns. General social issues (Yawar and Seuring, Chapter 27) and base-of-the-pyramid (Brix-Asala et al., Chapter 28) concerns in sustainable supply chains are core social issues. Humanitarian supply chains (Haavisto and Kovács, Chapter 29), focusing on helping people in need, are also important social dimensions of sustainable supply chain practice and research.

The final four chapters (Chapters 30-33) could have appeared anywhere in the Handbook due to their general applicability, and could be considered to cover miscellaneous topics. For example, regulatory policy relationships to sustainable supply chains (Darnall et al., Chapter 30) affects almost every issue from design and standards, to transportation and logistics. The multi-tier focus (Hofstetter and Grimm, Chapter 31) speaks to diffusion, social networks, standards and global issues. It is a supply chain sustainability topic of recent concern that is also difficult to manage. Green supplier development (Bai and Sarkis, Chapter 32) relates to collaboration and coordination, but incorporates technology, procurement, and many of the practices defined in the rest of the Handbook. This comprehensive topic is useful to help summarize the many topics and issues discussed throughout the Handbook, but with an optimistic focus of continuous improvement and diffusion of sustainable supply chains. Finally, the use of social enterprises within the supply chain provides an avenue of supply chain design and 
development by incorporating an institutional entrepreneur. This issue of transforming supply chains to become sustainable is what Chapter 33 (Jug), the final chapter, presents.

\subsection{SUMMARY}

Overall, this Handbook illustrates that there are a wide variety of practical and theoretical problems and solutions that arise in sustainable supply chain management study. The sustainable supply chain management field is still relatively young and continues to evolve - and evolve quickly.

New technologies, such as blockchain technology (Kouhizadeh and Sarkis, 2018; Saberi et al., 2018) and additive manufacturing (Sarkis and Zhu, 2018); new political transformations, such as the growth of China as a major player in global trade and protectionism in Europe and the United States; are causing new paradigms and ways of thinking. I realize that significant progress is still needed on this topic. I also realize that chapters on theory and methodology, in addition to analytical tools and decision-making, could have been included. Relationships to risk and resilience are also emerging concerns and topics in supply chain management. Many of these topics appear within the chapters, but more depth and detail could have been provided with stand-alone chapters. Handbooks just on these sustainable supply chain sub-topics are avenues for future work. Overall, I hope the interdisciplinary work included in this Handbook serves as an important piece of this evolution, as well as inspiring the serious pursuit of additional research and practice in the future.

This book project would not have come to fruition without the help of numerous people. I would first like to thank all the contributors for their patience and effort. I would like to thank the editorial staff at Edward Elgar Publishing for their help and guidance in putting together this important and needed tome.

\section{REFERENCES}

Ayres, R.U., and Kneese, A.V. (1969). Production, consumption, and externalities. American Economic Review, 59 (3), 282-297.

Bowen, H.R. (1953). Social Responsibilities of the Businessman. New York: Harper \& Row.

Brandenburg, M., Govindan, K., Sarkis, J., and Seuring, S. (2014). Quantitative models for sustainable supply chain management: developments and directions. European Journal of Operational Research, 233 (2), 299-312.

Carroll, A.B. (2008). A history of corporate social responsibility: concepts and practices. In A. Crane, D. Matten, A. McWilliams, J. Moon and D.S. Siegel (eds), The Oxford Handbook of Corporate Social Responsibility. Oxford: Oxford University Press, pp. 19-46.

Carson, R. (1962). Silent Spring. New York: Houghton Mifflin Harcourt.

Graves, L.M., Sarkis, J., and Zhu, Q. (2013). How transformational leadership and employee motivation combine to predict employee proenvironmental behaviors in China. Journal of Environmental Psychology, 35, 81-91.

Hoffman, A.J. (2001). From Heresy to Dogma: An Institutional History of Corporate Environmentalism. Palo Alto, CA: Stanford University Press.

Jabbour, C.J.C., and de Sousa Jabbour, A.B.L. (2016). Green human resource management and green supply chain management: linking two emerging agendas. Journal of Cleaner Production, 112, 1824-1833.

Kouhizadeh, M., and Sarkis, J. (2018). Blockchain practices, potentials, and perspectives in greening supply chains. Sustainability, 10 (10), 3652.

Saberi, S., Kouhizadeh, M., Sarkis, J., and Shen, L. (2018). Blockchain technology and its relationships 


\section{Handbook on the sustainable supply chain}

to sustainable supply chain management. International Journal of Production Research, 1-19. DOI: 10.1080/00207543.2018.1533261.

Sachs, J.D. (2012). From millennium development goals to sustainable development goals. Lancet, 379 (9832), 2206-2211.

Sarkis, J., and Zhu, Q. (2018). Environmental sustainability and production: taking the road less travelled. International Journal of Production Research, 56 (1-2), 743-759.

Sarkis, J., Zhu, Q., and Lai, K.H. (2011). An organizational theoretic review of green supply chain management literature. International Journal of Production Economics, 130 (1), 1-15.

Sinclair, U. (1906). The Jungle. New York: Doubleday, Jabber \& Co.

Welford, R. (1997). Hijacking Environmentalism: Corporate Responses to Sustainable Development. London: Earthscan. 